\title{
Morphometric and morphological characterization of chicken resources adapted to pastoral and agropastoral areas of southern Ethiopia
}

\author{
Amine Mustefa ${ }^{*, a}$, Hizkel Kenfo ${ }^{\mathrm{b}}$, Teklewold Belayhun ${ }^{\mathrm{a}}$, Abebe Hailu ${ }^{\mathrm{a}}$ and Abraham Assefa ${ }^{\mathrm{a}}$ \\ ${ }^{a}$ Ethiopian Biodiversity Institute, Addis Ababa, Ethiopia \\ ${ }^{b}$ Ethiopian Biodiversity Institute, Hawassa Biodiversity Center, Hawassa, Ethiopia
}

\begin{abstract}
Thirteen qualitative and six quantitative variables taken from 303 adult chickens (95 cocks and 208 hens) from three locations/districts were used to phenotypically characterize the indigenous chicken populations in pastoral areas of South Omo Zone, Ethiopia. The studied traits were influenced by the effect of location and sex, where chicken populations from Hamer district and females of all districts were the smallest and lightest. Qualitative characteristics of the studied chicken populations such as normal feather morphology and distribution, plain plumage pattern, flat head shape, triangular body shape, and dominant red eye, earlobe and plumage colour suggest that they constitute previously undescribed populations. Chest circumference, wingspan and body length were the three most important morphometric traits used in discriminating the studied chicken populations. On average, $61 \%$ of the sampled populations were classified correctly into their respective locations. The multivariate analysis results discriminate the chicken populations into two groups: the Hamer group and the Omo group (chickens from Bena Tsemay and Male districts). However, such grouping should be confirmed and advanced to ecotype level using further genetic characterization studies as the observed phenotypic differences might be due to genetic or environmental variations. Such confirmation is important to design breeding programmes (for sustainable utilization) specific to each ecotype.
\end{abstract}

Keywords: Characterization, Chicken, Discrimination, Ethiopia, Indigenous, Multivariate

Citation: Mustefa, A., Kenfo, H., Belayhun, T., Hailu, A., Assefa, A. (2021). Morphometric and morphological characterization of chicken resources adapted to pastoral and agropastoral areas of southern Ethiopia. Genetic Resources 2 (4), 72-84. doi: 10.46265/genresj.NDFM2712.

(C) Copyright 2021 the Authors.

This is an open access article distributed under the terms of the Creative Commons Attribution License (CC BY 4.0), which permits unrestricted use, distribution, and reproduction in any medium, provided the original author and source are

credited.

\section{Introduction}

Ethiopia, which is believed to be the main gate for most of the indigenous animal genetic resources from Asia to Africa, is one of the countries that possess a large number of livestock populations across the globe (EBI, 2016). Chicken are the most widely distributed livestock species in Ethiopia (EBI, 2016) and worldwide (FAO, 2012). The estimated chicken population size of the country in 2018/2019 was 59.42 million (6 million cocks) among which $85.68 \%$ were indigenous (Central Statistical Agency, 2019).

${ }^{*}$ Corresponding author: Amine Mustefa (aminemustefa32@gmail.com)
Poultry production in Ethiopia is one of the key livestock subsectors which plays an important role in terms of creating employment, subsidizing women, and improving the nutritional content of food. Due to the relatively low investment costs and the small quantity of land required for starting and running poultry production, it has become a suitable business for low-income farmers (FAO, 2019). However, this subsector is not contributing with its full capacity due to poor productivity of and less attention given to indigenous chickens. Therefore, many exotic chicken breeds were disseminated in the country with the objective of increasing production and productivity, becoming the major threat to diversity due to the dilution of indigenous genetic resources and yet providing minimum effect on production and productivity. 
Genetic improvement and conservation as well as sustainable utilization of the resources can also be achieved through the application of within-breed selection-based breeding programmes (McDowell, 1972). Identification, characterization and documentation of the rich Ethiopian chicken genetic resources are a prerequisite for genetic improvement, breed conservation and sustainable utilization through designing suitable breeding programmes (FAO, 2012). Outputs of such studies will provide insight into variation within and between populations, which is one of the key contributions to conservation and genetic improvement programmes; it is more likely to maintain diversity and bring genetic improvement in a population with high variability. According to EBI (2016), Ethiopia possesses seven indigenous chicken ecotypes: the Farta, Horro, Jarso, Konso, Mandura, Tepi and Tillili.

The small number of indigenous chicken ecotypes reported in the country can be attributed to the lack of comprehensive identification and characterization work on the diversity and potential of Ethiopian chicken populations. In addition, limitations in methodology and a lack of concrete conclusions in terms of population differentiation were observed in most of the earlier characterization studies. For example, the region-wide chicken characterization study by Melesse and Negesse (2011) did not measure the most important linear measurements (wingspan, body length, chest and shank circumference) and failed to provide concrete conclusions.

Measuring, recording and reporting values without strong comparisons, discriminations and conclusions cannot be taken as an input in diversity studies of any given animal breed or ecotype. Therefore, there is an urgent need for continued characterization of indigenous chicken genetic resources to understand their potential and reveal the relationships within and among populations. A short pilot survey performed by a team of Ethiopian Biodiversity Institute (EBI) researchers and South Omo Zone and district livestock experts hinted at the presence of unique chicken populations, in South Omo Zone, Ethiopia, that was not described before. Thus, the present study was aimed at characterizing the chicken populations found in the area based on the FAO (2012) guidelines for characterization of animal genetic resources.

\section{Materials and methods}

\section{Study areas}

This study was conducted in South Omo Zone, which is found in the Southern Nations Nationalities and Peoples Regional State (SNNPR) and situated in the southern part of Ethiopia (Figure 1). The capital of South Omo Zone, Jinka, is $750 \mathrm{~km}$ south of the capital city of the country (Addis Ababa). The zone has a total area of $2,241,731.598$ ha. The majority of the land is fertile and cultivated, with trees and bushes covering the remaining area. The zone falls in the arid and semi-arid category of the agroecological zone. Chickens are the most important animals for South Omo Zone pastoralists and agropastoralists next to ruminant animals (Tesfahun et al, 2017).

This study was conducted in three randomly selected pastoral and agropastoral districts (Bena Tsemay, Hamer and Male) of the eight districts found in the zone. Moreover, nine sampling sites (kebeles), three from each sampled district were selected based on the chicken population size data (Table 1). Two to three chicken were randomly selected for measurement from each randomly selected household within each kebele.

\section{Study ecotypes}

In literature, chicken populations of the current study area were generally classified as Konso chicken ecotypes (Dana et al, 2010). However, during the classification, samples were not taken from areas near the current study areas. Moreover, the results of our short pilot survey in South Omo Zone hinted at the presence of unique local chicken populations, which are different from Konso and were not described before. Furthermore, the studied chicken genetic resources are indigenous/local, producing, reproducing and surviving under the local environment since many years.

\section{Data collection}

The FAO guidelines for animal genetic resource characterization (FAO, 2012) were used to set the overall data collection procedures including the male to female ratio within the sampled chickens. The sampled chickens were randomly selected from flocks of representative households. Eleven qualitative traits (feather morphology and distribution, head shape, comb type and size, body shape, and colours of plumage body, earlobe, skin, shank, and eye), and six quantitative measurements (wingspan, body length, chest circumference, shank length, shank circumference, and live body weight) (Table 2) were recorded from 303 adult chicken (95 cocks and 208 hens) under the effect of district and sex.

During the measurements, animals were carefully handled by trained laborers and made to stand properly with parallel legs. The measurements were carried out by two researchers - one measuring and one recording data. At the same time, two other researchers handled the qualitative data recording. To minimize subjective error, all the measurements were taken by the same researcher throughout the study. Quantitative measurements were taken early in the morning before the animals were fed and watered using textile tape measures. Body weight was taken using sensitive digital weighing balances to the nearest of $0.05 \mathrm{~g}$.

\section{Data analysis}

Data entry and management were performed using Microsoft Excel(C) worksheets. Analysis of the quantitative measurements was carried out separately for both sexes and sex aggregated by fitting district as class variable. The UNIVARIATE procedure of Statistical Analy- 


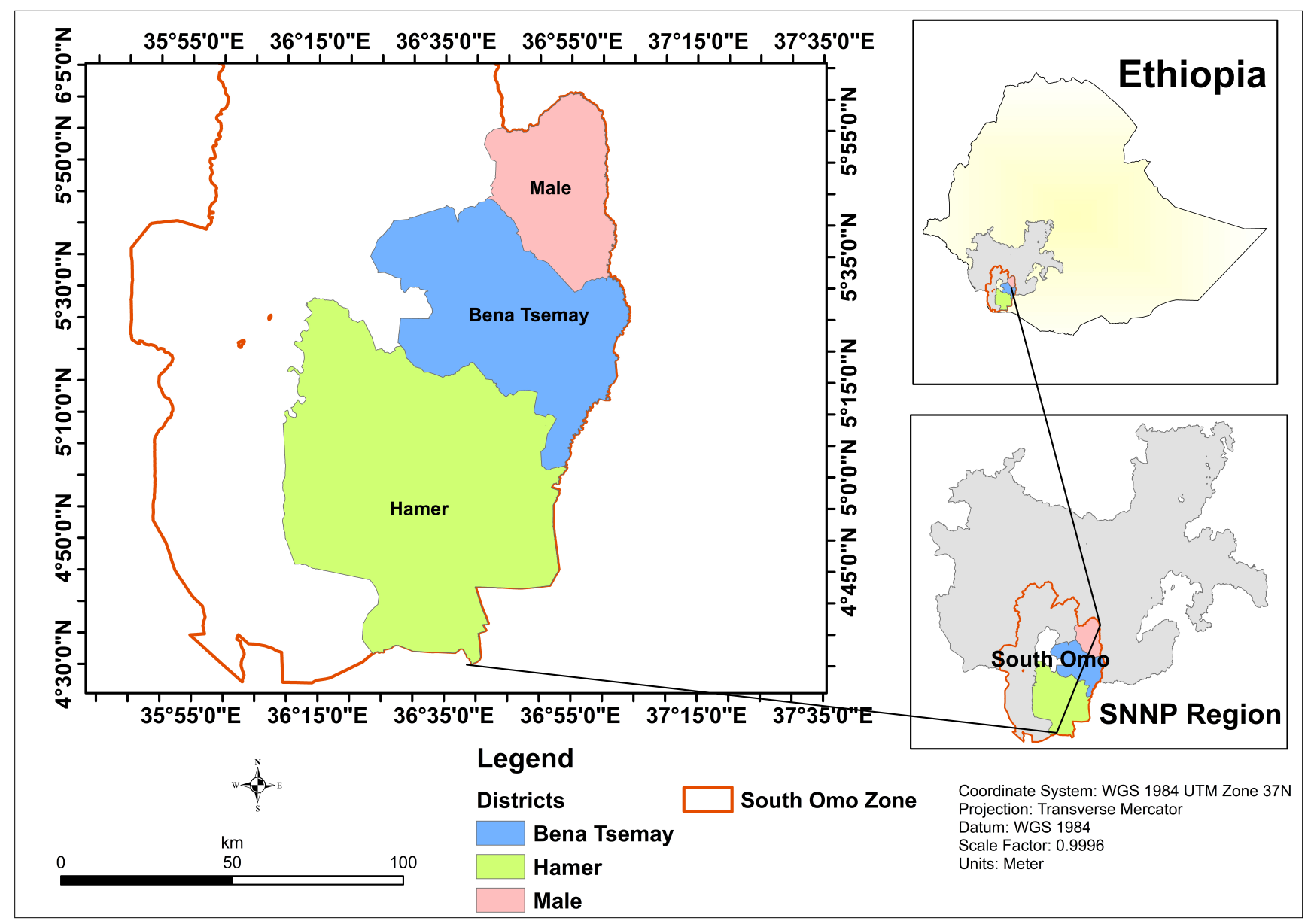

Figure 1. Map of the studied areas. The three study districts Bena Tsemay, Hamer and Male are located in South Omo, a zone within the Southern Nations Nationalities and Peoples Regional State (SNNP) in the southern part of Ethiopia.

sis Software (SAS) 9.0 (SAS Institute, 2002) was used to detect outliers and test the normality of the quantitative measurements data. Data on quantitative measurements and qualitative characteristics were analyzed using the General Linear Model (GLM) and the frequency (FREQ) procedures of SAS 9.0 software respectively. Least Square Means (LSM) of the linear measurements were separated using the adjusted Tukey-Kramer test (SAS Institute, 2002). Quantitative and qualitative data were analyzed using the following model: $Y_{i}=$ $\mu+A_{i}+e_{i}$ where $Y_{i}$ is an observation, $\mu$ is the overall mean, $A_{i}$ is the fixed effect of district and $e_{i}$ is the random error attributed to the $\mathrm{n}^{\text {th }}$ observation.
Forward selection procedure of the stepwise discriminant function analysis (STEPDISC) was used to find out the quantitative variables that better discriminate populations from different districts. The canonical discriminant function analysis (CANDISC) was also used to find out linear combination of quantitative variables that provide maximal separations between the districts. Pairwise squared Mahalanobis distances between locations were computed as: $D^{2}(i \mid j)=\left(x_{i}-x_{j}\right)^{\prime} \operatorname{cov}^{-1}\left(x_{i}-x_{j}\right)$. Where $D^{2}(i \mid j)$ is the distances between locations $i$ and $j, \operatorname{cov}^{-1}$ is the inverse of the covariance matrix of measured variables, $x_{i}$ and $x_{j}$ are the means of variables in the $i^{\text {th }}$ and $j^{\text {th }}$ populations. The scored canonical variables were used to plot pairs of canonical variables

Table 1. Land use, climatic factors and chicken population size of the three studied districts. Data from Hidosa et al (2020); Hidosa and Tesfaye (2018); Gezahegn and Bamud (2018); Derib (2017).

\begin{tabular}{llll}
\hline Variables & Bena Tsemay & Hamer & Male \\
\hline Land use & Agropastoralism & Pastoralism & Agropastoralism \\
Altitude $(\mathrm{m})$ & $500-1800$ & $450-1765$ & $600-1500$ \\
Temperature $\left({ }^{\circ} \mathrm{C}\right)$ & $17.3-28.9$ & $29-38$ & $18-35$ \\
Annual rainfall $(\mathrm{mm})$ & 1,167 & 400 & $800-1200$ \\
Chicken population size & 94,056 & 54,288 & 226,904 \\
\hline
\end{tabular}


Table 2. Six quantitative measurements definition and description of measuring devices used to characterize chicken populations. Adapted from FAO (2012).

\begin{tabular}{|c|c|c|c|c|}
\hline No. & Linear traits & Definition of quantitative morphological variables & Unit & $\begin{array}{l}\text { Measuring } \\
\text { device }\end{array}$ \\
\hline 1 & Wingspan & $\begin{array}{l}\text { Length between tips of right and left wings after both are } \\
\text { stretched out in full }\end{array}$ & $\mathrm{cm}$ & Measuring tape \\
\hline 2 & Body length & $\begin{array}{l}\text { Length between the tip of the rostrum maxillare (beak) and } \\
\text { that of the cauda (tail, without feathers); the bird's body } \\
\text { should be completely drawn throughout its length }\end{array}$ & $\mathrm{cm}$ & Measuring tape \\
\hline 3 & Chest circumference & Taken at the tip of the pectus (hind breast) & $\mathrm{cm}$ & Measuring tape \\
\hline 4 & Shank length & Length of the shank from the hock joint to the spur of either leg & $\mathrm{cm}$ & Measuring tape \\
\hline 5 & Shank circumference & Taken at the middle of the shank of either leg & $\mathrm{cm}$ & Measuring tape \\
\hline 6 & Body weight & Live body weight & $\mathrm{g}$ & Digital balance \\
\hline
\end{tabular}

to get visual interpretation of district differences. Percentage assignment of observations to known geographical locations (districts) and probabilities of misclassifications were evaluated by discriminant function analysis (DISCRIM).

\section{Results}

\section{Quantitative measurements}

Level of significance (P values) outputs for the effect of district and sex on the quantitative measurements analyzed for the chicken populations as a whole and separately for each sex are presented in Table 3. Results of the overall analysis show a significant effect of sex on the studied traits with dominance of cocks on all measured traits. Similarly, all studied traits were affected significantly by district in the sex-aggregated analysis. However, effect of district on wingspan and shank circumference was variable due to individuals' sex, where the cocks' wingspan and the hens' shank circumference were not significantly different across districts.

Least square means with the respective standard errors $(\mathrm{LSM} \pm \mathrm{SE})$ for the effect of district on the quantitative measurements of the chicken populations as a whole and separately for each sex are presented in Table 4. Cocks from Hamer district have the lowest values except for wingspan, while their counterparts from Bena Tsemay and Male districts were not significantly different in the measured traits. Body length, chest circumference, shank length and body weight of the Hamer hens were also lower than their counterparts from the other districts.

\section{Qualitative characteristics}

The hypothesis whether the qualitative characteristics of the studied chicken populations differ across districts and sexes was tested using chi-squared analysis. The results presented in Table 5 showed a significant effect of district and sex on most of the qualitative characteristics. The colour-related traits except earlobe colour of the cocks were significantly affected by district.

The percentages of qualitative characteristics in each district are presented in Table 6 and Table 7. Accordingly, silky feather morphology was observed on Bena Tsemay cocks. The majority of Bena Tsemay cocks possess single comb while one-fourth of the Male and Hamer cocks have a double comb type. The rectangular body shape was observed on almost half of the Bena Tsemay cocks, while the triangular body shape was dominant on cocks from other districts. All Hamer hens possess triangular body shapes while one-fourth of the Bena Tsemay hens had rectangular body shapes. The majority of the studied chicken populations have been characterized by normal feather morphology and distribution, plain plumage pattern, flat head shape, single comb type, and triangular body shape. The comb size of the studied chicken populations was sex-dependent; the majority of hens had small combs while cocks had medium-sized combs. The spur was also absent in the majority of hens from all districts.

Red plumage, earlobe and eye colour combined with yellow skin and shank colour, were dominantly observed in cocks from all districts (Table 7). On the other hand, red earlobe and eye colour with yellow shank colour were observed in the majority of hens in all districts. The majority of chickens in the Bena Tsemay and Male districts had yellow shank colour, while chicken populations from Hamer district had a large proportion with grey shank colour. Similarly, the skin colour of most of the chicken population from this study were yellow and white, with grey skin colour observed only in Hamer hens $(18.6 \%)$. The plumage body colour of Male and Hamer hens was dominated by grey colour while brown, red and black were observed in the majority of Bena Tsemay hens.

\section{Multivariate analysis for discrimination of chicken populations}

\section{Stepwise discriminant analysis}

Six quantitative measurements for both sexes were separately subjected to the STEPDISC procedure of SAS 9.0. Accordingly, all measurements in cocks and five measurements in hens were identified as the best discriminatory variables. These results were confirmed by Wilk's lambda test (Table 8) where all selected variables had highly significant $(\mathrm{P}<0.0001)$ contribution 
Table 3. Level of significance for the overallanalysis and separately for each sex. WS = Wingspan, BL = Body length, CC $=$ Chest circumference, $\mathrm{SL}=$ Shank length, $\mathrm{SC}=$ Shank circumference, $\mathrm{BW}=$ Body weight, $* \mathrm{p}<0.05,{ }^{* *} \mathrm{p}<0.01, * * * \mathrm{p}<0.0001$, NS $=$ Not Significant, CV = Coefficient of variation.

\begin{tabular}{llllllll}
\hline Traits & \multicolumn{3}{c}{ Overall chickens } & \multicolumn{2}{c}{ Cocks } & \multicolumn{2}{c}{ Hens } \\
& District & Sex & CV & District & CV & District & CV \\
\hline WS & $* * *$ & $* * *$ & 8.35 & NS & 7.63 & $*$ & 8.76 \\
BL & $* * *$ & $* * *$ & 6.88 & $* * *$ & 6.49 & $* * *$ & 7.08 \\
CC & $* * *$ & $* * *$ & 9.25 & $* * *$ & 9.85 & $* * *$ & 8.79 \\
SL & $* * *$ & $* * *$ & 10.16 & $* *$ & 8.45 & $* *$ & 11.05 \\
SC & $* *$ & $* * *$ & 10.56 & $* *$ & 12.19 & NS & 9.27 \\
BW & $* * *$ & $* * *$ & 21.60 & $* *$ & 22.93 & $* * *$ & 20.34 \\
\hline
\end{tabular}

Table 4. Pairwise mean comparison (least square means and standard errors (LSM \pm SE)) for the effect of district within each sex. Means within a column bearing different superscripts are significantly different; a is given to the highest value. $\mathrm{N}=$ number of observations, WS = Wingspan, $\mathrm{BL}=$ Body length, $\mathrm{CC}=$ Chest circumference, $\mathrm{SL}=$ Shank length, $\mathrm{SC}=\mathrm{Shank}$ circumference, $\mathrm{BW}$ $=$ Body weight.

\begin{tabular}{|c|c|c|c|}
\hline \multirow{2}{*}{ Traits } & \multicolumn{3}{|c|}{ District } \\
\hline & Bena Tsemay & Male & Hamer \\
\hline \multicolumn{4}{|l|}{ Cocks } \\
\hline $\mathrm{N}$ & 37 & 30 & 28 \\
\hline WS $(\mathrm{cm})$ & $41.14 \pm 0.52$ & $41.13 \pm 0.58$ & $42.86 \pm 0.60$ \\
\hline $\mathrm{BL}(\mathrm{cm})$ & $42.30 \pm 0.44^{a}$ & $42.00 \pm 0.49^{a}$ & $39.00 \pm 0.51^{b}$ \\
\hline $\mathrm{CC}(\mathrm{cm})$ & $30.05 \pm 0.48^{a}$ & $31.37 \pm 0.53^{a}$ & $27.36 \pm 0.55^{b}$ \\
\hline $\mathrm{SL}(\mathrm{cm})$ & $9.92 \pm 0.14^{a}$ & $10.37 \pm 0.15^{a}$ & $9.39 \pm 0.16^{b}$ \\
\hline $\mathrm{SC}(\mathrm{cm})$ & $4.92 \pm 0.10^{a}$ & $5.00 \pm 0.11^{a}$ & $4.50 \pm 0.11^{b}$ \\
\hline BW (g) & $1695.89 \pm 62.92^{a}$ & $1859.63 \pm 69.88^{a}$ & $1428.86 \pm 72.33^{b}$ \\
\hline \multicolumn{4}{|l|}{ Hens } \\
\hline $\mathrm{N}$ & 95 & 70 & 43 \\
\hline WS $(\mathrm{cm})$ & $36.06 \pm 0.32^{a b}$ & $35.50 \pm 0.38^{b}$ & $37.23 \pm 0.48^{a}$ \\
\hline $\mathrm{BL}(\mathrm{cm})$ & $38.09 \pm 0.27^{a}$ & $36.94 \pm 0.31^{b}$ & $35.02 \pm 0.40^{c}$ \\
\hline $\mathrm{CC}(\mathrm{cm})$ & $27.91 \pm 0.25^{a}$ & $27.67 \pm 0.29^{a}$ & $25.79 \pm 0.37^{b}$ \\
\hline $\mathrm{SL}(\mathrm{cm})$ & $8.28 \pm 0.09^{a}$ & $8.26 \pm 0.10^{a}$ & $7.67 \pm 0.14^{b}$ \\
\hline $\mathrm{SC}(\mathrm{cm})$ & $4.17 \pm 0.04$ & $4.20 \pm 0.05$ & $4.04 \pm 0.06$ \\
\hline BW (g) & $1373.87 \pm 27.78^{a}$ & $1400.16 \pm 32.36^{a}$ & $1124.23 \pm 41.29^{b}$ \\
\hline \multicolumn{4}{|c|}{ Both sexes } \\
\hline $\mathrm{N}$ & 132 & 100 & 71 \\
\hline WS $(\mathrm{cm})$ & $38.67 \pm 0.29^{b}$ & $38.27 \pm 0.33^{b}$ & $40.02 \pm 0.38^{a}$ \\
\hline $\mathrm{BL}(\mathrm{cm})$ & $40.24 \pm 0.24^{a}$ & $39.34 \pm 0.27^{b}$ & $37.06 \pm 0.32^{c}$ \\
\hline $\mathrm{CC}(\mathrm{cm})$ & $29.06 \pm 0.24^{a}$ & $29.28 \pm 0.27^{a}$ & $26.67 \pm 0.31^{b}$ \\
\hline $\mathrm{SL}(\mathrm{cm})$ & $9.14 \pm 0.08^{a}$ & $9.25 \pm 0.09^{a}$ & $8.54 \pm 0.11^{b}$ \\
\hline $\mathrm{SC}(\mathrm{cm})$ & $4.53 \pm 0.04^{a}$ & $4.58 \pm 0.05^{a}$ & $4.30 \pm 0.06^{b}$ \\
\hline BW (g) & $1543.70 \pm 28.31^{a}$ & $1610.42 \pm 31.98^{a}$ & $1282.62 \pm 37.06^{b}$ \\
\hline
\end{tabular}

in discriminating the chicken populations into separate groups. The stepwise discriminant function analysis also revealed that chest circumference, wingspan and body length were the three most important morphometric traits used in discriminating the chicken populations from different districts. However, body length, wingspan and body weight were the three most important variables used to discriminate the hens from different districts. Shank circumference was found to be less useful in discriminating the overall chicken populations due to its lowest discriminatory power (Table 8).

\section{Discriminant analysis}

The multivariate statistics and F approximations used in discriminating the studied chicken populations (cocks, hens and both sexes) are presented in Table 9. Accordingly, all the statistics used in discriminating the populations were significant. Higher F and Den DF values were calculated as the number of observations increased.

Results of a discriminant function analysis (Table 10) show the overall classification of individuals into a known location/district. Accordingly, the correct 
Table 5. Chi-square values and probabilities for the effect of classes on qualitative characteristics for the overall analysis and separately for both sexes. $X^{2}=$ chi-square value; $\mathrm{P}=$ probabilities; ${ }^{*} \mathrm{p}<0.05, * * \mathrm{p}<0.01, * * * \mathrm{p}<0.0001$, NS $=$ Not Significant.

\begin{tabular}{llllllllllc}
\hline \multirow{2}{*}{ Qualitative traits } & \multicolumn{3}{c}{ District } & \multicolumn{2}{c}{ Sex } & \multicolumn{2}{c}{ Cocks } & \multicolumn{2}{c}{ Hens } \\
& $X^{2}$ & $\mathbf{P}$ & $X^{2}$ & $\mathbf{P}$ & $X^{2}$ & $\mathbf{P}$ & $X^{2}$ & P \\
\hline Feather morphology & 7.93 & $*$ & 13.40 & $* *$ & 10.04 & $* *$ & - & - \\
Feather distribution & 7.91 & NS & 3.00 & NS & 3.20 & NS & 5.05 & NS \\
Plumage pattern & 5.25 & NS & 1.85 & NS & - & - & 4.85 & NS \\
Head shape & 8.65 & NS & 3.19 & NS & 2.66 & NS & 6.79 & NS \\
Comb type & 25.35 & $* *$ & 22.53 & $* *$ & 17.34 & $* *$ & 12.99 & NS \\
Comb size & 3.73 & NS & 135.2 & $* * *$ & 5.43 & NS & 7.48 & NS \\
Body shape & 27.72 & $* * *$ & 8.41 & $*$ & 11.06 & $*$ & 24.14 & $* * *$ \\
Spur presence & 3.16 & NS & 118.6 & $* * *$ & 2.51 & NS & 7.32 & $*$ \\
Plumage colour & 36.13 & $* * *$ & 50.70 & $* * *$ & 22.18 & $*$ & 26.09 & $* *$ \\
Earlobe colour & 17.38 & $* *$ & 20.24 & $* *$ & 6.55 & NS & 16.57 & $*$ \\
Skin colour & 49.06 & $* * *$ & 17.87 & $* * *$ & 6.71 & $*$ & 49.90 & $* * *$ \\
Shank colour & 52.07 & $* * *$ & 17.73 & $* *$ & 27.69 & $* *$ & 40.17 & $* * *$ \\
Eye colour & 80.30 & $* * *$ & 5.50 & NS & 30.03 & $* * *$ & 57.02 & $* * *$ \\
\hline
\end{tabular}

Table 6. Percentages for the qualitative characteristics of the chicken populations from different districts.

\begin{tabular}{|c|c|c|c|c|c|c|}
\hline \multirow{2}{*}{ Qualitative traits } & \multicolumn{2}{|c|}{ Cocks } & \multirow[b]{2}{*}{ Hamer } & \multicolumn{3}{|c|}{ Hens } \\
\hline & Bena Tsemay & Male & & Bena Tsemay & Male & Hamer \\
\hline \multicolumn{7}{|c|}{ Feather morphology } \\
\hline Normal & 83.8 & 100 & 100 & 100 & 100 & 100 \\
\hline Silky & 16.2 & 0 & 0 & 0 & 0 & 0 \\
\hline \multicolumn{7}{|c|}{ Feather distribution } \\
\hline Normal & 94.6 & 100 & 100 & 91.6 & 94.3 & 97.7 \\
\hline Naked neck & 5.4 & 0 & 0 & 6.3 & 1.4 & 2.3 \\
\hline Crest & 0 & 0 & 0 & 2.1 & 4.3 & 0 \\
\hline \multicolumn{7}{|l|}{ Plumage pattern } \\
\hline Plain & 100 & 100 & 100 & 95.8 & 100 & 100 \\
\hline Barred & 0 & 0 & 0 & 3.2 & 0 & 0 \\
\hline Barring & 0 & 0 & 0 & 1.0 & 0 & 0 \\
\hline \multicolumn{7}{|l|}{ Head shape } \\
\hline Flat & 100 & 96.7 & 92.9 & 92.6 & 98.6 & 95.4 \\
\hline Crust & 0 & 0 & 0 & 5.3 & 1.4 & 0 \\
\hline Snake & 0 & 3.3 & 7.1 & 2.1 & 0 & 4.6 \\
\hline \multicolumn{7}{|l|}{ Comb type } \\
\hline Single & 86.5 & 63.3 & 53.6 & 75.8 & 58.6 & 62.8 \\
\hline Pea & 2.7 & 0 & 14.3 & 8.4 & 18.6 & 16.3 \\
\hline Rose & 10.8 & 16.7 & 10.7 & 12.6 & 20.0 & 18.6 \\
\hline V-shape & 0 & 0 & 0 & 3.2 & 0 & 0 \\
\hline Double & 0 & 20.0 & 21.4 & 0 & 2.8 & 2.3 \\
\hline \multicolumn{7}{|l|}{ Comb size } \\
\hline Small & 35.1 & 20.0 & 21.4 & 85.3 & 97.1 & 93.0 \\
\hline Medium & 37.9 & 53.3 & 64.3 & 13.7 & 2.9 & 7.0 \\
\hline Large & 27.0 & 26.7 & 14.3 & 1.0 & 0 & 0 \\
\hline \multicolumn{7}{|l|}{ Body shape } \\
\hline Blocky & 0 & 3.3 & 0 & 2.1 & 0 & 0 \\
\hline Rectangular & 45.9 & 16.7 & 17.9 & 26.3 & 7.1 & 0 \\
\hline Triangular & 54.1 & 80.0 & 82.1 & 71.6 & 92.9 & 100 \\
\hline \multicolumn{7}{|l|}{ Spur presence } \\
\hline Absent & 27.0 & 43.3 & 42.9 & 89.5 & 98.6 & 97.7 \\
\hline Present & 73.0 & 56.7 & 57.1 & 10.5 & 1.4 & 2.3 \\
\hline
\end{tabular}


Table 7. Percentages of some colour-related qualitative traits of the chicken populations from different districts.

\begin{tabular}{|c|c|c|c|c|c|c|}
\hline \multirow{2}{*}{ Qualitative traits } & \multicolumn{3}{|c|}{ Cocks } & \multicolumn{3}{|c|}{ Hens } \\
\hline & Bena Tsemay & Male & Hamer & Bena Tsemay & Male & Hamer \\
\hline \multicolumn{7}{|l|}{ Plumage colour } \\
\hline Black & 5.4 & 0 & 0 & 20.0 & 11.4 & 9.3 \\
\hline Brown & 5.4 & 0 & 0 & 25.3 & 17.2 & 9.3 \\
\hline Grey & 10.8 & 30.0 & 17.9 & 15.8 & 30.0 & 44.2 \\
\hline Red + White & 8.1 & 10.0 & 25.0 & 1.0 & 7.1 & 11.6 \\
\hline Red & 46.0 & 56.7 & 53.6 & 25.3 & 18.6 & 16.3 \\
\hline White & 24.3 & 3.3 & 3.6 & 12.6 & 15.7 & 9.3 \\
\hline \multicolumn{7}{|l|}{ Earlobe colour } \\
\hline White & 5.6 & 6.7 & 3.6 & 15.0 & 18.6 & 32.6 \\
\hline Red & 88.8 & 66.6 & 71.4 & 77.5 & 72.8 & 51.1 \\
\hline Red + White & 5.6 & 26.7 & 25.0 & 3.8 & 4.3 & 16.3 \\
\hline Black & 0 & 0 & 0 & 3.7 & 4.3 & 0 \\
\hline \multicolumn{7}{|l|}{ Skin colour } \\
\hline Grey & 0 & 0 & 0 & 0 & 0 & 18.6 \\
\hline White & 43.2 & 16.7 & 21.4 & 63.2 & 31.4 & 48.8 \\
\hline Yellow & 56.8 & 83.3 & 78.6 & 36.8 & 68.6 & 32.6 \\
\hline \multicolumn{7}{|l|}{ Shank colour } \\
\hline Yellow & 91.9 & 96.7 & 50.0 & 56.8 & 70.0 & 37.2 \\
\hline Black & 2.7 & 0 & 10.7 & 20.0 & 12.9 & 16.3 \\
\hline White & 5.4 & 3.3 & 17.9 & 20.0 & 4.3 & 9.3 \\
\hline Grey & 0 & 0 & 21.4 & 3.2 & 12.8 & 37.2 \\
\hline \multicolumn{7}{|l|}{ Eye colour } \\
\hline Red & 62.2 & 100 & 92.9 & 73.7 & 95.7 & 72.1 \\
\hline Blue & 0 & 0 & 7.1 & 0 & 0 & 7.0 \\
\hline Brown & 0 & 0 & 0 & 1.0 & 2.9 & 18.6 \\
\hline White & 5.4 & 0 & 0 & 3.2 & 0 & 2.3 \\
\hline Yellow & 32.4 & 0 & 0 & 22.1 & 1.4 & 0 \\
\hline
\end{tabular}

classification of cocks into their location/district ranged from $51 \%$ in Bena Tsemay to $75 \%$ in Hamer. The overall average error rate was $39 \%$, and $61 \%$ of the individuals were classified correctly. An average of $64 \%$ and $58 \%$ of the sampled cocks and hens were classified correctly into their corresponding districts, respectively. A higher error rate of $55 \%$ was observed in Bena Tsemay hens, while a lower error rate (23\%) was obtained from the classification of Hamer district hens.

\section{Canonical discriminant analysis}

Different multivariate statistics (including canonical correlation and eigenvalues), the coefficient values for each trait used, and class mean outputs using the first two canonical structures are shown in Table 11. The first canonical structure (Can 1) explains the majority (85.4\%) of the variability among the three districts (84.5\% for cocks and $84.3 \%$ for hens). Can 1 also produces the greatest multiple correlation (60.2\%) with the classes that was achieved by using the linear combination of the quantitative traits; the values were $72.7 \%$ for cocks and $55.5 \%$ for hens. The results revealed that Can 1 separates the chicken populations (class means) from different districts better than Can 2.
The pairwise squared Mahalanobis distances between locations/districts for analysis groups presented in Table 12 were highly significant $(\mathrm{P}<0.0001)$. The shortest distance (0.6) was calculated between the chicken populations of Bena Tsemay and Male districts; 1.36 for cocks and 0.46 for hens. On the other hand, the chicken populations from Hamer district were more distantly related to the others (2.87 and 3.71 from Bena Tsemay and Male districts, respectively).

\section{Discussion}

\section{Quantitative measurements}

The quantitative measurements taken have produced reliable information on characterization, evaluation and differentiation of the studied chicken populations. In line with most reports, these measurements were significantly affected by the location sampled. The longest wings and smallest body size of the Hamer chickens make them significantly different from the chicken populations of the other two locations. These long wings stretched from the small body size can be recorded and reported as the unique characteristics 
Table 8. Summary of the stepwise discriminant function analysis; ascending order of traits used in discriminating the chicken populations from different districts.

\begin{tabular}{|c|c|c|c|c|c|c|c|}
\hline Group & Step & Variable entered & Partial R-Square & F value & $\mathbf{P}>\mathbf{F}$ & Wilks' Lambda & $\mathbf{P}<$ Lambda \\
\hline \multicolumn{8}{|l|}{ Cocks } \\
\hline & 1 & Chest circumference & 0.2353 & 14.15 & $<0.0001$ & 0.7647 & $<0.0001$ \\
\hline & 2 & Wingspan & 0.1907 & 10.72 & $<0.0001$ & 0.6189 & $<0.0001$ \\
\hline & 3 & Body length & 0.1886 & 10.46 & $<0.0001$ & 0.5022 & $<0.0001$ \\
\hline & 4 & Shank length & 0.1267 & 6.46 & 0.0024 & 0.4386 & $<0.0001$ \\
\hline & 5 & Body weight & 0.0568 & 2.65 & 0.0764 & 0.4137 & $<0.0001$ \\
\hline & 6 & Shank circumference & 0.0542 & 2.49 & 0.0884 & 0.3912 & $<0.0001$ \\
\hline \multicolumn{8}{|l|}{ Hens } \\
\hline & 1 & Body length & 0.1661 & 20.42 & $<0.0001$ & 0.8339 & $<0.0001$ \\
\hline & 2 & Wingspan & 0.0877 & 9.80 & $<0.0001$ & 0.7608 & $<0.0001$ \\
\hline & 3 & Body weight & 0.1162 & 13.34 & $<0.0001$ & 0.6724 & $<0.0001$ \\
\hline & 4 & Shank length & 0.0366 & 3.84 & 0.0231 & 0.6478 & $<0.0001$ \\
\hline & 5 & Chest circumference & 0.0207 & 2.13 & 0.1220 & 0.6344 & $<0.0001$ \\
\hline & - & Shank circumference & 0.0005 & 0.05 & 0.9498 & - & - \\
\hline \multicolumn{8}{|c|}{ Both sexes } \\
\hline & 1 & Chest circumference & 0.1006 & 16.78 & $<0.0001$ & 0.8994 & $<0.0001$ \\
\hline & 2 & Wingspan & 0.1890 & 34.83 & $<0.0001$ & 0.7294 & $<0.0001$ \\
\hline & 3 & Body length & 0.1068 & 17.82 & $<0.0001$ & 0.6515 & $<0.0001$ \\
\hline & 4 & Body weight & 0.0637 & 10.10 & $<0.0001$ & 0.6100 & $<0.0001$ \\
\hline & 5 & Shank length & 0.0523 & 8.17 & 0.0004 & 0.5781 & $<0.0001$ \\
\hline & - & Shank circumference & 0.0005 & 0.08 & 0.9259 & - & - \\
\hline
\end{tabular}

Table 9. Multivariate statistics and F approximations used in discrimination of the chicken populations. DF = degrees of freedom; $\mathrm{P}=$ Probability.

\begin{tabular}{|c|c|c|c|c|c|c|}
\hline Group & Statistic & Value & F value & DF & Den DF & $\mathbf{P}>\mathbf{F}$ \\
\hline \multicolumn{7}{|l|}{ Cocks } \\
\hline & Wilks' Lambda & 0.3912 & 8.68 & 12 & 174 & $<0.0001$ \\
\hline & Pillai's Trace & 0.6986 & 7.87 & 12 & 176 & $<0.0001$ \\
\hline & Hotelling-Lawley Trace & 1.3265 & 9.54 & 12 & 132.28 & $<0.0001$ \\
\hline & Roy's Greatest Root & 1.1217 & 16.45 & 6 & 88 & $<0.0001$ \\
\hline \multicolumn{7}{|l|}{ Hens } \\
\hline & Wilks' Lambda & 0.6340 & 8.53 & 12 & 400 & $<0.0001$ \\
\hline & Pillai's Trace & 0.3916 & 8.16 & 12 & 402 & $<0.0001$ \\
\hline & Hotelling-Lawley Trace & 0.5367 & 8.91 & 12 & 308.04 & $<0.0001$ \\
\hline & Roy's Greatest Root & 0.4459 & 14.94 & 6 & 201 & $<0.0001$ \\
\hline \multicolumn{7}{|c|}{ Both sexes } \\
\hline & Wilks' Lambda & 0.5778 & 15.51 & 12 & 590 & $<0.0001$ \\
\hline & Pillai's Trace & 0.4560 & 14.57 & 12 & 592 & $<0.0001$ \\
\hline & Hotelling-Lawley Trace & 0.6722 & 16.48 & 12 & 455.81 & $<0.0001$ \\
\hline & Roy's Greatest Root & 0.5696 & 28.10 & 6 & 296 & $<0.0001$ \\
\hline
\end{tabular}

of Hamer chickens, which might be related to their mothering ability.

A previous study by Dana et al (2010) which describes Konso as a chicken ecotype took only two quantitative measurements (the body weight and shank length). In terms of body weight both cocks and hens of the current study were heavier than the Konso chicken ecotype where the body weights of the Konso cocks and hens were $1,411 \mathrm{~g}$ and $1,011 \mathrm{~g}$ respectively (Dana et al, 2010). Such phenotypic variations in body weight hint at the presence of genetic diversity that needs to be conserved and can also be used as a base in attaining genetic improvement through selection. Therefore, in terms of body weight, the current chicken populations were different from the Konso chicken ecotype.

On the other hand, their shank length measurements were comparable. According to Melesse and Negesse (2011), the shank length is considered a good indicator of adaptation to lowland areas and skeletal development, which is related to the amount of meat a chicken 
Table 10. Number and (percent) of observations classified into districts.

\begin{tabular}{llrrrr}
\hline Group & From district & Bena Tsemay & \multicolumn{1}{c}{ Hamer } & \multicolumn{1}{c}{ Male } & \multicolumn{1}{l}{ Total } \\
\hline Cocks & & & & & \\
& Bena Tsemay & $19(51 \%)$ & $7(19 \%)$ & $11(30 \%)$ & $37(100 \%)$ \\
& Hamer & $3(11 \%)$ & $21(75 \%)$ & $4(14 \%)$ & $28(100 \%)$ \\
& Male & $8(27 \%)$ & $2(7 \%)$ & $20(66 \%)$ & $30(100 \%)$ \\
& Total & $30(32 \%)$ & $30(32 \%)$ & $35(36 \%)$ & $95(100 \%)$ \\
& Error rate & $49 \%$ & $25 \%$ & $34 \%$ & $36 \%$ \\
& & & & & \\
Hens & Bena Tsemay & $43(45 \%)$ & $18(19 \%)$ & $34(36 \%)$ & $95(100 \%)$ \\
& Hamer & $5(11 \%)$ & $33(77 \%)$ & $5(11 \%)$ & $43(100 \%)$ \\
& Male & $24(34 \%)$ & $9(13 \%)$ & $37(53 \%)$ & $70(100 \%)$ \\
& Total & $72(35 \%)$ & $60(29 \%)$ & $76(36 \%)$ & $208(100 \%)$ \\
& Error rate & $55 \%$ & $23 \%$ & $47 \%$ & $42 \%$ \\
& & & & & \\
& Bena Tsemay & $65(49 \%)$ & $22(17 \%)$ & $45(34 \%)$ & $132(100 \%)$ \\
& Hamer & $9(13 \%)$ & $52(73 \%)$ & $10(14 \%)$ & $71(100 \%)$ \\
& Male & $31(31 \%)$ & $8(8 \%)$ & $61(61 \%)$ & $100(100 \%)$ \\
& Total & $105(35 \%)$ & $82(27 \%)$ & $116(38 \%)$ & $303(100 \%)$ \\
& Error rate & $51 \%$ & $27 \%$ & $39 \%$ & $39 \%$ \\
\hline
\end{tabular}

Table 11. Multivariate statistics, canonical coefficients of the quantitative variables, and class means outputs of the two canonical structures separately for each sex. Can = Canonical structure.

\begin{tabular}{lrrrrrr}
\hline & \multicolumn{2}{c}{ Cocks } & \multicolumn{2}{c}{ Hens } & \multicolumn{2}{c}{ Both sexes } \\
& Can 1 & \multicolumn{1}{c}{ Can 2 } & Can 1 & Can 2 & Can 1 & Can 2 \\
\hline Multivariate statistics & & & & & & \\
Canonical correlation & 0.7271 & 0.4122 & 0.5553 & 0.2885 & 0.6024 & 0.3051 \\
Eigenvalue & 1.1217 & 0.2047 & 0.4459 & 0.0908 & 0.5696 & 0.1026 \\
Proportion & 0.8457 & 0.1543 & 0.8309 & 0.1691 & 0.8473 & 0.1527 \\
Cumulative & 0.8457 & 1.0000 & 0.8309 & 1.0000 & 0.8473 & 1.0000 \\
F value & 8.68 & 3.60 & 8.53 & 3.65 & 15.51 & 6.08 \\
P>F & $<0.0001$ & 0.0052 & $<0.0001$ & 0.0035 & $<0.0001$ & $<0.0001$ \\
Traits & & & & & & \\
Wingspan & -0.3191 & 0.0338 & -0.2780 & 0.1110 & -0.3280 & 0.0350 \\
Body weight & 0.0004 & -0.0029 & 0.0019 & -0.0031 & 0.0015 & -0.0028 \\
Body length & 0.1247 & 0.5403 & 0.0915 & 0.4719 & 0.0560 & 0.5070 \\
Chest circumference & 0.1727 & -0.0725 & 0.1483 & 0.0356 & 0.1828 & 0.0089 \\
Shank length & 0.5074 & -0.8638 & 0.3943 & -0.5278 & 0.3388 & -0.7575 \\
Shank circumference & 0.4542 & 0.8747 & -0.1134 & 0.0512 & -0.0147 & 0.1737 \\
Class (district) mean & & & & & & \\
Bena Tsemay & 0.4234 & 0.5273 & 0.3164 & 0.2933 & 0.2980 & 0.3400 \\
Male & 0.9488 & -0.5150 & 0.3679 & -0.3858 & 0.5594 & -0.3871 \\
Hamer & -1.5761 & -0.1450 & -1.298 & -0.0200 & -1.3419 & -0.0869 \\
\hline & & & & & &
\end{tabular}

can carry. This shows their high adaptability to the lowland areas of the pastoral and agropastoral community.

Comparable, higher and lower values of wingspan, body length, chest circumference, shank length and shank circumference measurements were reported in indigenous chickens in different parts of the country. However, surprisingly low values were also reported. For example, Negassa et al (2014) reported 7.35-8.17 cm of wingspan and 22.6-24.2 cm of body length for chickens in southeastern Ethiopia. Similarly, Halima et al (2007) reported 12.67-15.83 cm of wingspan and 0.53-0.93 $\mathrm{cm}$ of shank circumference for chickens in northern Ethiopia.

\section{Effect of sex}

Cocks were bigger and heavier than hens, which follows Rensch's rule (Rensch, 1950) where the males of an individual species are generally larger than the females. Such differences between cocks and hens may be attributed to the differences in hormone secretion, 
Table 12. Squared Mahalanobis distance between districts; output of the multivariate analysis calculated using the quantitative measurements. $* * *$ indicates significance of the distance calculations at $\mathrm{p}<0.0001$.

\begin{tabular}{|c|c|c|c|c|}
\hline Group & From district & $\begin{array}{l}\text { Bena } \\
\text { Tsemay }\end{array}$ & Male & Hamer \\
\hline \multicolumn{5}{|l|}{ Cocks } \\
\hline & Bena Tsemay & 0 & & \\
\hline & Male & $1.36^{* * *}$ & 0 & \\
\hline & Hamer & $4.45 * * *$ & $6.51 * * *$ & 0 \\
\hline \multicolumn{5}{|l|}{ Hens } \\
\hline & Bena Tsemay & 0 & & \\
\hline & Male & $0.46 * *$ & 0 & \\
\hline & Hamer & $2.70 * * *$ & $2.91 * * *$ & 0 \\
\hline \multicolumn{5}{|l|}{$\begin{array}{l}\text { Both } \\
\text { sexes }\end{array}$} \\
\hline & Bena Tsemay & 0 & & \\
\hline & Male & $0.60 * * *$ & 0 & \\
\hline & Hamer & $2.87 * * *$ & $3.71 * * *$ & 0 \\
\hline
\end{tabular}

which leads to enlargement of muscle mass and skeletal development (Baneh and Hafezian, 2009). These results were in line with the reports of Bekele et al (2015), Getu et al (2014), Negassa et al (2014), and Melesse and Negesse (2011), Dana et al (2010) and Halima et al (2007) on different indigenous chicken populations of Ethiopia. Similarly, sexual dimorphism was reported for most traits with males having higher values when compared to the females in other species of Ethiopia, including goats (Mustefa et al, 2019), cattle (Mustefa et al (2020b)), donkeys (Mustefa et al (2020a)) and sheep (Hailu et al, 2020).

\section{Qualitative characteristics}

Observable qualitative characteristics, in addition to the quantitative measurements, have allowed us to characterize, identify and differentiate the studied chicken populations. Dana et al (2010), Bekele et al (2015), Melesse and Negesse (2011) reported normal feather morphology and distribution in the majority of indigenous chicken populations in Ethiopia's southern region that are comparable with the results of the current study. Melesse (2000) described the nakedneck gene as one of the main genes responsible for heat tolerance of some Ethiopian indigenous chicken populations by improving and enhancing heat dissipation due to the reduction in feather coverage. However, the current study also revealed the adaptation of indigenous chickens to the local pastoral and agropastoral lowland areas with a lower frequency of naked-neck chickens. This lower frequency of nakedneck chicken in the current study area specifically, as well as in the country in general, may also be a factor for their poor productivity (Ajang et al, 1993). Similarly, Yunis and Cahaner (1999) reported the probability of attaining higher egg and/or meat production in chicken with reduced feathering due to the saved feather protein.
Qualitative deviations were also observed between Konso ecotype and the current chicken populations. Firstly, the comb types, which vary greatly depending on the breed, are also a great indicator of a chicken's health. Bright fleshy combs indicate physical strength and good health. Combs also help chickens regulate their body temperature - those with large combs are able to circulate blood faster through their combs, which helps to release body heat. This is why chickens adapted to warm environments have larger combs (like single combs and buttercup combs) while breeds from colder areas have smaller combs (like pea and rose combs) (Vaughn, 2019). The majority of chickens from the current study area were single-combed while Dana et al (2010) reported a higher frequency of pea-combed chickens in the Konso chicken ecotype. Dana et al (2010) also reported humid lowland to wet highland ecological zones as local areas of the Konso chicken ecotype. The comb size of the studied chicken populations was found to be sex-dependent where hens of a given population had smaller combs than the cocks. This was supported by Bell (2002) who reported the association of comb size with gonadal development and intensity of light.

The earlobe colour of a chicken can determine the colour of the egg that it will lay. For example, if the chicken has a red earlobe, it will lay a brown-shelled egg and if it has a white earlobe, it will lay a white-shelled egg (Bell, 2002). Red earlobe colour was observed in the majority of chickens from the current study, while Dana et al (2010) reported equal frequency of red and white earlobe colours in Konso chicken ecotype. The observation of a higher proportion of hens with white earlobe colour than the cocks in each district was due to the sex-linked nature of the trait (Luo et al, 2018). Among the populations of the current study, a higher proportion of white earlobes was observed in Hamer hens than the others, which might be due to their distinction from the others as earlobe colour is a breedspecific trait, though it could also be affected by the nutritional status of the chicken populations (Melesse and Negesse, 2011).

The triangular body shape was dominantly found in the current study while the results of Dana et al (2010) reported blocky body shape for the majority of the Konso chicken ecotype. On the other hand, similar qualitative characteristics, like flat head shape, were observed on both Konso chicken ecotypes (Dana et al, 2010) and the current chicken populations.

Chicken populations, breeds and breeding groups can be identified by their plumage colours due to their decorative qualities. Plumage colour is also a key trait during the interaction of chickens due to their welldeveloped visual perception of the world (Makarova et al, 2019). In agreement with most Ethiopian reports, several plumage colours were found in the current study area with a higher frequency of red-coloured cocks. On the other hand, the predominance of grey (faded white and black) colour observed in hens is in line with the reports of Halima et al (2007). The diverse 
plumage colours in the current study, which might be due to either genetic or environmental factors, showed the presence of diverse genetic resources, which can be an input in conservation and genetic improvement programmes for sustainable use.

Bekele et al (2015), Getu et al (2014), Halima et al (2007), Dana et al (2010) reported yellow as the most widespread shank and skin colour in different indigenous chicken populations of Ethiopia, which agrees with the current findings. According to Hammond and Harshaw (1941), a chicken's shank and skin colour are influenced by breed, quantity of xanthophyll pigment in the diet, and quantity of a pigmentationsuppressing factor in the diet. Bell (2002) stated that yellow shank colour is due to nutritional carotenoid colourants in the epidermis when the melanic pigment is absent. Similarly, variable shades of black colour are the result of melanic pigment in the dermis and epidermis; if the black colourant is in the dermis and yellow in the epidermis, greenish shanks will appear. However, if both these pigments are completely absent, the shanks will be white (Bell, 2002).

Commonly, red, yellow and black eye colours are due to the three pigments in the form of hemoglobin, carotenoids and melanin respectively. Red eye colour is influenced by the degree of iridic vessels injection and hemoglobin content of the blood (Nelson, 1947). According to Nelson (1947), when chickens suffer from general anemia, a smaller amount of red colouration will be noted due to loss of blood volume. Therefore, the dominant red eye colour observed in the current study is a confirmation that these chicken populations were free from such suffering. As per the same author, continual egg production can decrease the yellow factor in eye colour. Therefore, the yellow eye colour chicken from Bena Tsemay district (27\%) might indicate restrictions in egg productivity.

\section{Multivariate analysis}

The use of more quantitative measurements during the discrimination analysis approaches the results towards reality. This is supported by the current results, where only one quantitative measurement in hens had low discriminatory power.

In line with reports by Mustefa et al (2020b) on Raya cattle (61\%) and Hailu et al (2020) on Tigray sheep (66\%), the discriminant function analysis allowed the classification of an average $61 \%$ of the studied individuals into their respective locations. The observed highest classifications of individuals into their respective districts in Hamer cocks and hens $(75 \%$ and $77 \%$ respectively) showed their distinctness from the others due to the unique characteristics they possess. However, the lowest classifications (45\% and 53\%) were recorded in hens from Bena Tsemay and Male district indicating strong similarities between them.

The highly significant and longest pairwise Mahalanobis distances between districts indicate the accuracy of the calculations and the distinctness of the popula- tions from each other in a measurable group difference for the considered quantitative measurements. Accordingly, the longest distances of Hamer chickens from the other two chicken populations in this study showed its distinctness.

In conclusion, the main contribution of this diversity study is the provision of information and data for breed differentiation, conservation and sustainable utilization of the chicken ecotypes in the districts, as well as the collation of information and data available on chicken ecotypes of Ethiopia. Accordingly, the chicken populations can be categorized phenotypically into two groups: the Hamer group and the Omo group (which includes the indigenous chicken populations from Bena Tsemay and Male districts). However, such differences in phenotypic performances might be either due to genetic or environmental variations. Therefore, we cannot conclude that the differences are solely due to genetic variations. Thus, genetic characterization is recommended to understand their potential and the within- and among-population genetic diversity and population structures.

\section{Data availability}

As baseline data for further research and development work, these data will be made available in the country's focal institute for indigenous animal genetic resources, the Ethiopian Biodiversity Institute (EBI) and the global Domestic Animal Diversity Information System (DADIS) databases.

\section{Acknowledgments}

The authors are highly grateful to the Ethiopian Biodiversity Institute (EBI) for funding the work. Our special appreciation also goes to the farmers for providing their animals for this work for free. We also take this opportunity to appreciate the animal science experts at zonal, district and kebele level for their endless help during the data collection. A special word also goes to our friend and work partner Mr. Tadesse Hunduma for mapping the study area.

\section{Author contributions}

All authors contributed to the study conception and design. Material preparation and data collection were performed by Amine Mustefa, Hizkel Kenfo, and Teklewold Belayhun. Data analysis and writing the first draft of the manuscript was performed by Amine Mustefa and all authors commented on previous versions of the manuscript. All authors read and approved the final manuscript.

\section{Conflict of interest statement}

The authors declare no conflict of interest. 


\section{References}

Ajang, O. A., Prijono, S., and Smith, W. K. (1993). The effect of dietary protein level on growth and body composition of fast and slow feathering broiler chickens. British Poultry Science 34, 73-91. doi: https: //doi.org/10.1080/00071669308417564

Baneh, H. and Hafezian, S. H. (2009). Effect of environmental factor on growth traits in Ghezel sheep. African Journal of Biotechnology 8, 2903-2907. url: https://www.ajol.info/index.php/ajb/article/view/ 60943.

Bekele, G., Kebede, K., Ameha, and N (2015). On-farm Phenotypic Characterization of Indigenous Chicken and their Production System in Bench Maji Zone. Science, Technology and Arts Research Journal 4, 68-73. doi: http://dx.doi.org/10.4314/star.v4i1.10

Bell, D. D. (2002). Anatomy of the Chicken. In Commercial chicken meat and egg production, ed. Bell, D., D., Weaver, and and, W. D., (USA: Springer, Boston, MA), 41-58.

Central Statistical Agency (2019). Agricultural Sample Survey 2018/19. Report on Livestock and Livestock Characteristics. In Statistical Bulletin No. 588, volume II, Central Statistical Agency, Addis Ababa, Ethiopia.

Dana, N., Dessie, T., Van Der Waaij, H. L., and Van Arendonk, A. M. J. (2010). Morphological features of indigenous chicken populations of Ethiopia. Animal Genetic Resource 46, 11-23. doi: https://doi.org/10. 1017/S2078633610000652

Derib, G. (2017). Production and Marketing Systems of Goat in Hamer Woreda, South Omo Zone, Southern Ethiopia. url: https://doi.org/10.20372/ nadre: 1554185414.61.

EBI (2016). Ethiopian National Strategy and Plan of Action for conservation and utilization of Animal Genetic Resources (Addis Ababa, Ethiopia: Ethiopian Biodiversity Institute). url: https://www.ebi.gov.et/wpcontent/uploads/2013/ 01/Final\%20ENSAP_final_submitted\%20(1).pdf.

FAO (2012). Phenotypic characterization of animal genetic resources. In FAO Animal Production and Health Guidelines No. 11, FAO, Rome, Italy.

FAO (2019). Poultry Sector Ethiopia. In FAO Animal Production and Health Livestock Country Reviews n.11, FAO, Rome.

Getu, A., Alemayehu, K., and Wuletaw, Z. (2014). Phenotypic characterization of indigenous chicken ecotypes in the north Gondar zone. Ethiopia. Animal Genetic Resources 54, 43-51. doi: https://doi.org/10. 1017/S2078633614000113

Gezahegn, B. and Bamud, K. (2018). Identification of Major Crop Production Constraints in Bena-Tsemay District, South Omo Zone, Southern Ethiopia. . Food Science and Quality Management 74. url: https://www.iiste.org/Journals/ index.php/FSQM/article/view/41847.

Hailu, A., Mustefa, A., Aseged, T., Assefa, A., Sinkie, S., and Tsewene, S. (2020). Phenotypic characterization of sheep populations in Tahtay Maichew district.
Northern Ethiopia. Genetic Resources 1(2), 13-23. doi: https://doi.org/10.46265/genresj.SHBD3744.

Halima, H., Neser, F. W. C., Van Marle-Koster, E., Dekock, and A (2007). Phenotypic variation of indigenous chicken populations in northwest Ethiopia. Tropical Animal Health and Production 39, 507-513. doi: https://doi.org/10.1007/ s11250-007-9032-2

Hammond, J. C. and Harshaw, H. M. (1941). Some Factors Influencing $\mathrm{S}$ hank a nd $\mathrm{S}$ kin $\mathrm{C}$ olor i $\mathrm{n}$ the Growing Chicken. Poultry Science 20, 437-444. doi: https://doi.org/10.3382/ps.0200437

Hidosa, D., Hailu, S., 'reagain, O., and J (2020). Goat Feed Inventory and Feed Balance in Hamer and Bena-Tsemay Woreda of South Omo Zone, South Western Ethiopia. Acta Scientific Veterinary Sciences 2(6), 28-43. url: https://actascientific.com/ASVS/ ASVS-02-0069.php.

Hidosa, D. and Tesfaye, Y. (2018). Assessment Study on Livestock Feed Resource, Feed Availability and Production Constraints in Maale Woreda in South Omo Zone. Journal of Fisheries and Livestock Production 6(2). doi: https:// doi.org/10.4172/2332-2608.1000269

Luo, W., Xu, J., Li, Z., Xu, H., Lin, S., Wang, J., Ouyang, H., Nie, Q., and Zhang, X. (2018). GenomeWide Association Study and Transcriptome Analysis Provide New Insights into the White/Red Earlobe Color Formation in Chicken. Cell Physiology and Biochemistry 46, 1768-1778. doi: https://doi.org/10. $1159 / 000489361$

Makarova, A. V., Mitrofanova, O. V., Vakhrameev, A. B., and Dementeva, N. V. (2019). Molecular-genetic bases of plumage coloring in chicken. Vavilov Journal of Genetics and Breeding 23, 343-354. doi: https://doi. org/10.18699/VJ19.499

McDowell, R. E. (1972). Improvement of Livestock Production In Warm Climates. W.H. Freeman \& Co., San Francisco.

Melesse, A. (2000). Comparative studies on performance and physiological responses of Ethiopian indigenous (Angete-Melata) chickens and their F1crosses to long-term heat exposure (Martin-Luther University of Halle-Wittenberg, Halle-Saale, Germany) . url: https://www.cabdirect.org/cabdirect/ abstract/20036794426.

Melesse, A. and Negesse, T. (2011). Phenotypic and morphological characterization of indigenous chicken populations in southern region of Ethiopia. Animal Genetic Resources 49, 19-31. doi: https://doi.org/10. 1017/S2078633611000099

Mustefa, A., Assefa, A., Misganaw, M., Getachew, F., Abegaz, S., Hailu, A., and Emshaw, Y. (2020a). Phenotypic Characterization of Donkeys in Benishangul Gumuz National Regional State. Online Journal of Animal and Feed Research 10(1), 25-35. doi: https: //dx.doi.org/10.36380/scil.2020.ojafr4

Mustefa, A., Belayhun, T., Melak, A., Hayelom, M., Tadesse, D., Hailu, A., and A, A. (2020b). Phenotypic 
characterization of Raya cattle in northern Ethiopia. Tropical Animal Health and Production 53, 48-48. doi: https://doi.org/10.1007/s11250-020-02486-1

Mustefa, A., Gizaw, S., Banerjee, S., Abebe, A., Taye, M., Areaya, A., and Besufekad, S. (2019). Growth performance of Boer goats and their F1 and F2 crosses and backcrosses with Central Highland goats in Ethiopia. Livestock Research for Rural Development 31(89). url: http://www.lrrd.org/lrrd31/6/amine31089.html.

Negassa, D., Melesse, A., and Banerjee, S. (2014). Phenotypic characterization of indigenous chicken populations in Southeastern Oromia Regional State of Ethiopia. Animal Genetic Resources 55, 101-113. doi: https://doi.org/10.1017/s2078633614000319

Nelson, N. M. (1947). Normal Eye Color in the Chicken. Poultry Science 26, 61-66. doi: https://doi.org/10. 3382/ps.0260061

Rensch, B. (1950). Die Abhangigkeit der relative sexual differenz von der korpergrosse. Bonner Zoologische Beitrage 1, 58-69.

SAS Institute (2002). url: https://www.sas.com/enus/ software/stat.html.

Tesfahun, B., Kebede, K., and Effa, K. (2017). Traditional goat husbandry practice under pastoral systems in South Omo zone, southern Ethiopia. Tropical Animal Health and Production 49, 625-632. doi: https://doi. org/10.1007/s11250-017-1240-9

Vaughn, K. (2019). url: https://www. communitychickens.com/chicken-comb-types-

zbw1912ztil/.

Yunis, R. and Cahaner, A. (1999). The effects of nakedneck (Na) and frizzle (F) genes on growth and meat yield of broilers, and their interactions with ambient temperatures and potential growth rate. Poultry Science 78, 1347-1352. doi: https://doi.org/10.1093/ ps/78.10.1347 